\title{
The DNA-based diet
}

Cite as: CMAJ 2017 January 9;189:E40-1. doi: 10.1503/cmaj.109-5352

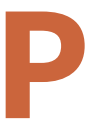

erhaps you're a "protein seeker." Maybe eggs are your "hero food," or it might be spinach. This is the type of "personalized nutrition" information based on DNA and blood analysis that Habit, a new California-based company, will soon be delivering to health-conscious consumers - with a salmon fillet and avocado on the side.

Some researchers in the field of nutrition genomics are skeptical, suggesting that even if the concept holds promise, the science has not advanced enough to allow companies to craft an optimal diet for any given person. But Habit is optimistic that its "patent-pending and proprietary platform," which considers more than 60 biomarkers, can make good on its promise.

"Habit's optimal goal is to increase people's understanding of their bodies from a systems biology perspective and what foods and nutrients work best for them, helping them achieve optimal health," Neil Grimmer, founder and CEO of Habit, said in an email.

The six-step process "to a better you" begins with a home test kit to collect samples of your blood and DNA, which you send to a lab for analysis. The test results, combined with self-reported health information and goals, are fed into Habit's "nutrition intelligence engine" to determine which foods and nutrients are best for your body. You can then contact one of Habit's registered dietitians for further guidance. The company will even prepare and deliver meals tailored to your personal nutrition profile. Finally, there is an app that allows you to share your "Habit journey" and connect with other "like-bodied wellness-seekers".

In an essay called "The Personalized Nutrition Revolution Starts Now," Grimmer explained why he created Habit. In his early 30s, Grimmer was a triathlete, and chose foods to fuel his training and the grueling races that followed. But when he got busy running an organic baby-food company, fitness and nutrition fell to the wayside. In his 40 s, he found himself 50 pounds heavier and on the precipice of serious health problems.

With the help of doctors and nutritionists, Grimmer turned to genetic testing and blood work for insight into his personal dietary needs. He discovered he had trouble processing sugars, starches and refined carbohydrates. His coffee habit also came to an end, thanks to a genetic marker indicating he was slow to metabolize caffeine. He created a personalized nutrition plan, which helped him lose weight and improve his overall health and well-being.

"My personal wake-up call led me to epiphany that the method of my personal health transformation should be made available to everyone across the nation," wrote Grimmer. "The catch was, none of this was easy, or inexpensive, or accessible. This needed to change."

The company will officially launch its services in the Bay Area of California in early 2017. It will cost $\$ 299$ (US) for the initial testing, food recommendations and a session with a dietician. The food-delivery service and follow-up tests cost extra.

Habit's business plan is backed by science, said Grimmer. He cited a 2016 study in The American Journal of Clinical Nutrition that found people who received personalized nutrition advice were more likely to adhere to a specific diet (in this case, the Mediterranean diet). A related paper in the International Journal of Epidemiology found that providing personalized nutrition information based on diet, lifestyle and genotype "produced larger and more appropriate changes in dietary behaviour than a conventional approach."

According to the Academy of Nutrition and Dietetics, however, practical applications of nutritional genomics, such as those soon to be offered by Habit, are "not yet ready for routine dietetics practice." In a position statement, the academy stated that determining personalized dietary interventions is complex, requiring not only advanced knowledge in genetics, but also additional information, including family history and personal risk factors. Direct-to-

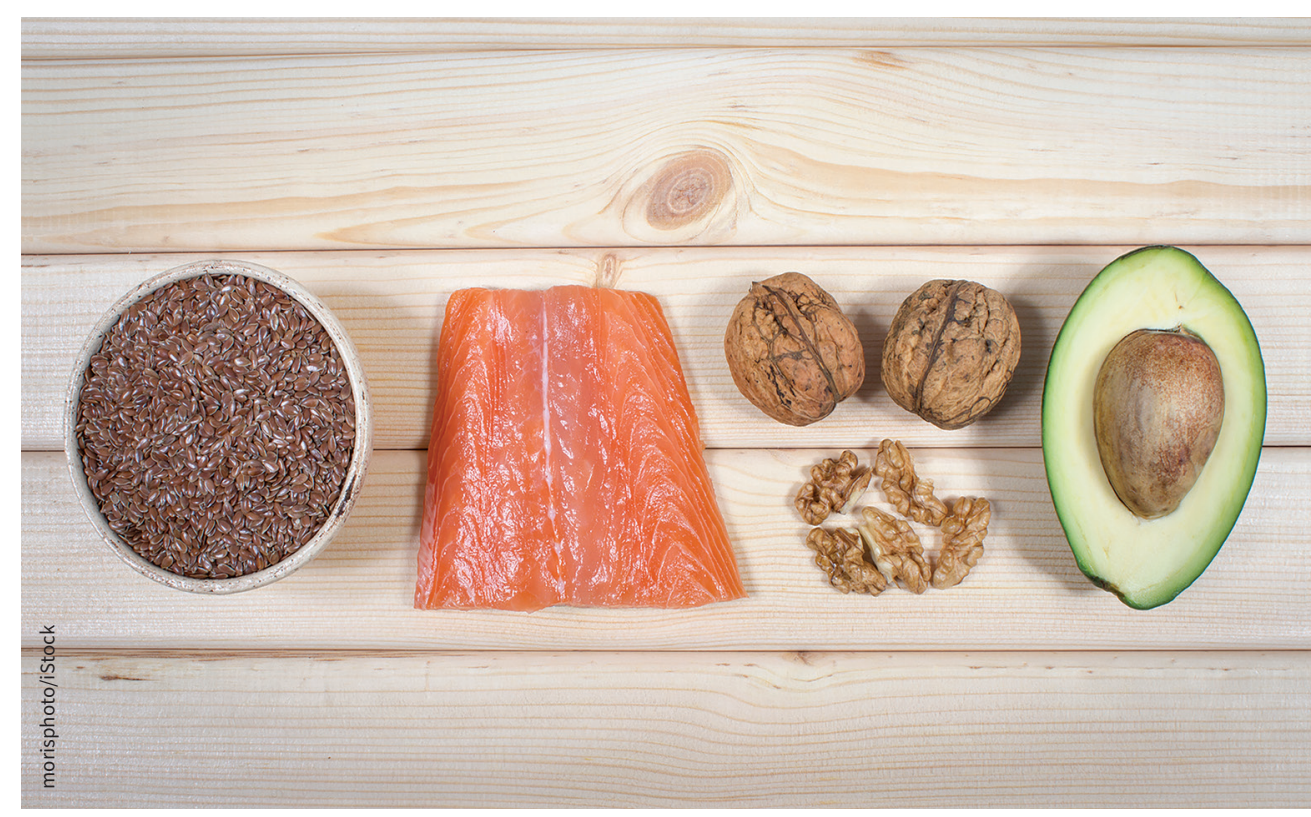

Can DNA and blood tests reveal which foods are optimal for an individual's health? 
consumer genetic testing is not closely regulated, warned the agency, which also suggested that more evidence is needed to ensure personalized dietary recommendations result in actual health benefits and cause no harm.

"While there is interesting research going on in this area, most agree that the marketing of these kinds of services is premature. There is little data to suggest this kind of testing can have a meaningful clinical impact," Timothy Caulfield, a Can- ada Research Chair in Health Law and Policy, said in an email.

Even if the information provided by a company like Habit were accurate, it would likely have little impact on changing consumer behavior, said Caulfield, pointing to a 2016 systematic review published in BMJ. The paper examined 18 studies that monitored changes in people's risk-reducing behaviour after receiving information about their genetic risks of disease. It found no significant effects on behaviours such as quitting smoking, improving diet and increasing physical activity.

"We live in an era when few people eat enough fruits and vegetables, a significant portion of our society is obese, and many consume way too much junk food," noted Caulfield. "For me, focusing on the marginal benefits - if any - of following a genetic-informed diet borders on the absurd."

Roger Collier, CMAJ 